\title{
La economía sin ambages en la gestión del patrimonio
}

\author{
Gabriel Morate Martín | director del Programa de Conservación del Patrimonio Histórico Español de la Fundación Caja Madrid
}

URL de la contribución <www.iaph.es/revistaph/index.php/revistaph/article/view/3423>

Siendo malos tiempos para la lírica, conviene empezar por ella para explicar lo obvio en un foro como éste: que el patrimonio histórico, producto humano que no se puede reproducir, es un elemento clave para la libertad y el bienestar de una sociedad. El patrimonio, que comparte raíz latina con palabras como padre y patria, está conformado por el conjunto de bienes que permiten conocer nuestra historia, sentirnos parte de algo en el pasado y en el futuro y tener un suelo que poder pisar. No padecer como sociedad esa terrible enfermedad que es el alzheimer. Muchos de estos bienes son además hermosos y satisfacen la necesidad que tiene el ser humano de Belleza. Todas las tiranías, que siempre han sabido de su importancia, han sentido con mayor o menor intensidad la necesidad de destruirlo o instrumentalizarlo, que viene a ser casi lo mismo.

Pero son malos tiempos para la lírica. Son tiempos para la economía. Por ello, teniendo el patrimonio una dimensión económica innegable, podemos afirmar, en respuesta al "¿y ahora qué?" que plantea el debate propuesto, que o el sector del patrimonio histórico incorpora sin ambages la economía a su gestión o lo harán otros por él, como así parece que va sucediendo, menos dados a la lírica. Conviene por tanto preguntarse por la economía en una doble dirección: en primer lugar, la del impacto que el patrimonio tiene en el bienestar de la gente y en el desarrollo económico. Buscando la forma de medir el valor intangible del patrimonio, profundizando en los análisis de su contribución a la creación de empleo y al producto interior bruto (PIB), siendo capaces, en definitiva, de mostrar a los responsables de la Hacienda Pública y la Economía cuál es el coste de oportunidad de no invertir en patrimonio frente a inversiones de otro tipo. En segundo lugar, conviene preguntarse por el papel que tiene la economía, definida como el arte de la administración eficaz y razonable de las cosas, en la gestión del patrimonio, definido como el conjunto de bienes recibidos por herencia.

El análisis económico de la cultura como disciplina autónoma de la ciencia económica surge en EEUU a mediados de los años 70 del pasado siglo. Y surge, porque sólo nos acordamos de santa Bárbara cuando truena, como reacción casi desesperada del sector cultural ante la grave crisis económica de esos años. Este interés por el impacto de la cultura en la economía tiene su reflejo en España a partir de la década de los noventa. Hay diversos estudios que analizan con profusión las llamadas industrias culturales y su contribución a la riqueza nacional, pero todavía faltan análisis rigurosos y periódicos sobre el impacto económico en concreto del patrimonio histórico, que tiende a medirse por la contribución al PIB y al empleo.

Es verdad que cada vez son más los estudios singulares que se realizan sobre el impacto económico de monumentos o sitios históricos concretos. No es menos cierto que en los últimos años han surgido varios análisis del patrimonio histórico español en su conjunto desde una perspectiva económica o que las administraciones públicas mejoran poco a poco sus anuarios estadísticos sobre la materia. Pero aún así, son pocos los estudios y muy frecuentemente no son comparables. De esta manera, podemos concluir que las políticas y la gestión del patrimonio se hacen todavía sin el concurso de la economía, como si los gastos en patrimonio se legitimaran por sí mismos y carecieran de coste de oportunidad.

Incluso hoy, en un escenario de fortísimos ajustes presupuestarios y de parálisis del sector, la dimensión económica del patrimonio inspira recelo, cuando no aversión, a muchos profesionales del patrimonio. Como si, a pesar de la estrecha vinculación que existe entre economía y patrimonio, introducir aquella dimensión en la gestión de 
éste fuera incompatible con la correcta conservación y llevara inevitablemente a la banalización de la cultura. Como si incorporar la economía a la gestión del patrimonio, a la que se han sumado sin prevención algunas otras ramas del saber como la física y química aplicada o la biología, pusiera en riesgo la profunda significación del patrimonio. Como si mezclar economía y patrimonio fuera algo perverso y una suerte de pecado de simonía, consistente en comerciar con cosas espirituales y sagradas. Como si la caída en picado de la inversión en restauración, la supresión de tantos proyectos de investigación o el cierre parcial o total de monumentos, sitios o museos, nada tuvieran que ver, en fin, con la economía.

A pesar de que dos no se juntan si uno no quiere, hay que decir también que tampoco los economistas se han sentido atraídos por una realidad considerada hasta hace no mucho como improductiva. Ante un tipo de bienes, los integrantes del patrimonio histórico, difíciles de valorar en términos de dinero.

Lo cierto es que en la actual coyuntura patrimonio y economía están condenados a entenderse y apoyarse; y, como queda dicho, el sector del patrimonio debe incorporar sin ambages la economía a la gestión. La crisis económica acabará algún día, pero cuando eso ocurra las políticas de protección y tutela habrán cambiado, ya lo están haciendo, y los porcentajes de gasto público en conservación del patrimonio con respecto al gasto público total no volverán a ser los existentes con anterioridad a la crisis. De esta manera, el sector del patrimonio está obligado a ser más razonable y eficaz en el gasto, habrá de valorar el coste de oportunidad de sus inversiones en investigación, restauración o difusión, se verá obligado a generar recursos por actividad propia, a encontrar financiación y a importar y adaptar en consecuencia procedimientos y herramientas del mundo de los negocios y la administración de empresas.

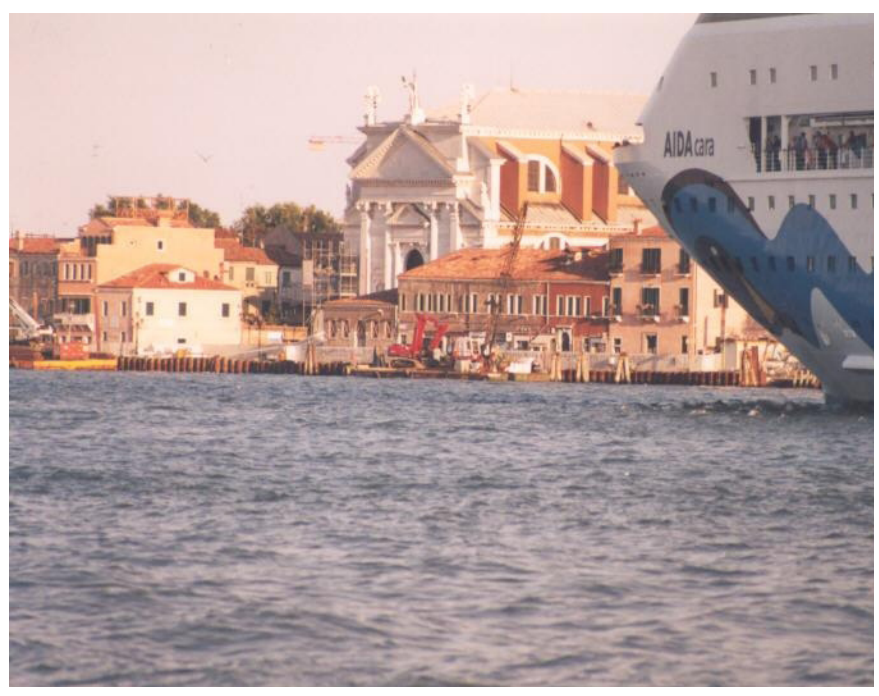

Si el sector del patrimonio no incorpora la economía y el turismo a la gestión, el turismo y la economía gestionarán el patrimonio a su manera. En la imagen, Venecia | Foto: Gabriel Morate

Venimos de una década, la anterior a la crisis, de 1997 a 2007, en la que los niveles de inversión en el patrimonio han sido extraordinarios. Se han restaurado miles de monumentos, se ha trabajado en multitud de yacimientos arqueológicos, se han renovado gran parte de los museos arqueológicos y de bellas artes provinciales y casi todos los museos nacionales, se han recuperado barrios enteros, como el casco viejo de Pamplona, y hasta ciudades enteras, como Cartagena. Pero también, durante esa misma década, con gran complejo de Sísifo, ha habido que volver a restaurar los mismos monumentos ya restaurados, ante la ausencia de medidas que garanticen un mantenimiento continuado; muchos de esos monumentos han permanecido cerrados tras su restauración, se han construido decenas de espectaculares equipamientos culturales sin programación y centenares de museos y centros de interpretación sin público. La economía, que en resumidas cuentas no es más que la ciencia social que versa sobre la toma de decisiones 
a debate ¿el patrimonio cultural en crisis? ¿y ahora qué? | coordina Gabriel Morate Martín

para satisfacer necesidades y el destino de los escasos recursos disponibles, no puede ser una disciplina ajena a la conservación del patrimonio histórico.

Igualmente condenados a entenderse y apoyarse están, en un ámbito en el que a menudo lo público se confunde con lo estatal, el sector público y el sector privado. Un entendimiento que debe ser radicalmente distinto al actual, porque los instrumentos para fomentar este acercamiento han sido y son bastante ineficaces, proviniendo el $90 \%$ del gasto en preservación del patrimonio de los poderes públicos.

Y este porcentaje, atención, resulta desolador. Significa en cierto modo que, a pesar del creciente interés ciudadano por la conservación del patrimonio, el 90\% de las actividades de investigación, protección, conservación, difusión y gestión dependen de la subvención pública y de los presupuestos del Estado.

Los instrumentos del Estado para fomentar la participación del sector privado son variados, estando de plena actualidad la posible reforma de la ley de incentivos fiscales al patrocinio y mecenazgo. No es lugar este texto para hacer siquiera una sucinta relación de ellos. Entre otras cosas, porque a esa exigua lista de instrumentos de fomento de la iniciativa privada, habría que sumarle también la lista de instrumentos de protección y tutela que hacen extraordinariamente dificultosa y poco atractiva la participación del sector privado en este campo.

Pero sí debe decirse que, en este ámbito de la cultura, depositar todas las esperanzas de una mayor participación del sector privado en la capacidad de desgravación fiscal de las aportaciones hechas es una ilusión vana. Primero, porque la participación del sector privado no debe limitarse sólo al patrocinio y al mecenazgo, sino que debe abrirse también al ámbito de la gestión. Por otra parte, se hace necesario encontrar nuevas fórmulas de colaboración entre las administraciones públicas y los propietarios privados. Segundo, porque no es cierto que la motivación principal de una empresa a la hora de patrocinar una obra de restauración o una exposición sea la de desgravarse fiscalmente parte de su aportación económica.

Mucho menos cierto resulta en relación con otro tipo de incentivos fiscales que éstos sean el acicate de la actividad de interés social que pretenden estimular. Es decir, que ni el propietario de un BIC arregla su casa con la intención de desgravar parte del gasto realizado, ni el socio de una asociación de utilidad pública paga su cuota por lo mismo.

La realidad es que los incentivos fiscales son pocos y cobardes, no afectan a la mayor parte del patrimonio histórico, sino sólo a la pequeña parte que goza de la máxima protección jurídica, y no actúan como incentivos, sino como pequeñas compensaciones. Cosa distinta son los incentivos directos, pero en este ámbito el instrumento predominante hasta ahora en la conservación del patrimonio ha sido la subvención pública.

Por tanto, una mayor participación del sector privado, de los ciudadanos, las empresas y el llamado tercer sector exige ante todo un profundo cambio en la mentalidad de la administración cultural, que, sin saberlo, hace tan difícil la iniciativa privada como difícil es abrir una paladar en Cuba. Exige también abrir a la iniciativa privada los ámbitos de la gestión e incluso de la propiedad allí donde sea posible, deseable y bajo la tutela siempre y con la colaboración de los poderes públicos. Sin duda este profundo cambio en el modelo de conservación y gestión al que nos vemos abocados, sea por vernos arrastrados por la tendencia neoliberal del momento, porque la crisis económica no deje otra opción o por convencimiento propio, requiere un enriquecedor debate técnico sobre cómo hacerlo, al margen de estériles debates ideológicos. El Consorcio de Mérida o el IAPH no son buenas instituciones por ser públicas, como tampoco lo son el National Trust o la Fundación Santa María la Real por ser privadas.

El patrimonio histórico genera numerosas actividades económicas relacionadas con su investigación, conservación y puesta en valor. Por otra parte, está relacionado 
a debate ¿el patrimonio cultural en crisis? ¿y ahora qué? | coordina Gabriel Morate Martín

de modo muy diverso con otras actividades económicas como pueden ser la compra-venta de antigüedades, de manera muy directa, o, de forma más indirecta la publicidad, el sector audiovisual, el editorial y, en definitiva, el de todas las llamadas industrias culturales.

Pero la manera más ilustrativa de mostrar la dimensión económica del patrimonio, y su potencial, es relacionándolo tanto con el turismo como con la calidad y cantidad de bienes culturales que atesora España.

El turismo en general es un sector clave para el Producto Bruto Mundial y la generación de empleo. Su crecimiento es tan espectacular como espectacular es el crecimiento demográfico, pero, sobre todo, la transformación de la sociedad. La Organización Mundial de Turismo aún no ha llegado a ofrecer datos fiables sobre los índices del turismo cultural con relación al turismo global, dada la dificultad metodológica de su obtención, pero sí señala repetidamente que es uno de los sectores de más rápido crecimiento y posibilidades de futuro.

En España el flujo de visitantes a los principales monumentos tiene importantes tasas de crecimiento en la última década. Así mismo, de acuerdo con datos de 2007 aportados por los profesores Alonso Hierro y Martín Fernández, el consumo turístico cultural no residente y residente estuvo en 49.000 millones de euros, siendo el gasto público en conservación del patrimonio de 1.700 millones. Dos indicadores muy ilustrativos por tanto a la hora de revelar la dimensión económica del patrimonio. Dos indicadores que, poniendo la lupa en una comarca como Albarracín, de 4.900 habitantes, alcanzan el valor anual de 8 millones de euros de consumo turístico cultural y de una media anual de 450.000 euros de gasto en preservación de su patrimonio.

Pongamos ahora en relación esta dimensión con la cantidad y calidad de los bienes culturales de España. El patrimonio histórico español constituye, utilizando el término que acuñara David Throsby, uno de los mayores stocks de capital cultural del mundo, compuesto de bienes físicos y bienes inmateriales. Un stock, sólo comparable a Italia y Francia, de bienes económicos y productivos, pero de naturaleza peculiar, tal y como han señalado varios autores:

\section{- Son bienes heterogéneos.}

- No son renovables.

- Su ciclo de vida es extraordinariamente largo, lo que influye en los costes asociados a su depreciación y conservación.

- Su depreciación no depende automáticamente de su utilidad.

- El ejercicio del derecho de propiedad sobre ellos está fuertemente limitado.

- La mayor parte de ellos no se pueden cambiar de sitio, lo que significa que la actividad económica o el empleo que generan no es "deslocalizable"...

- Y gran parte de su valor -educativo, de legado a nuestros hijos, de opción y de prestigio y cohesión social ligada a la identidad-, la mayor parte de su valor, es intangible. Porque ¿cómo contar en euros la emoción que produce ponerse delante de las Meninas o tener testimonios materiales que nos permiten saber que todo lo que nos sucede como hombres no es nada nuevo ni distinto de lo que les sucedió a los que nos precedieron? Afortunadamente, sabemos también, gracias a un físico, Einstein, que no todo lo que se puede contar cuenta, ni todo lo que cuenta se puede contar.

Tenemos pues un potencial de recursos extraordinario, y en la lista de Patrimonio Mundial somos el segundo país más importante del mundo, solamente detrás de Italia. Sin embargo, los índices de consumo turístico cultural de países de nuestro entorno con menos patrimonio son superiores al nuestro. Siendo las causas de esta contradictoria realidad variadas, cabe apuntar dos principales: la primera es que el patrimonio de esos países está en su conjunto mejor conservado, cosa razonable, ya que son más ricos y llevan muchos más años que nosotros conservando su 


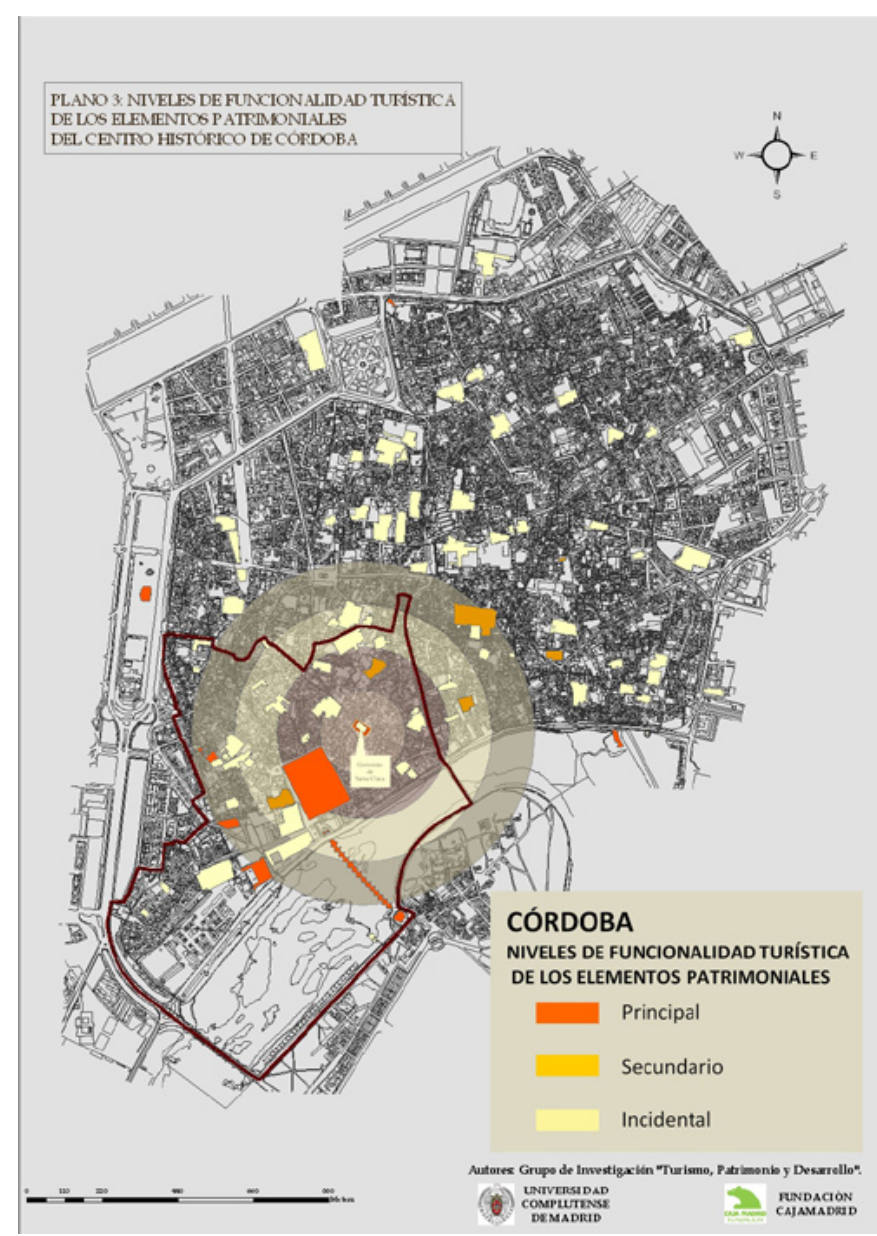

Estudio de funcionamiento Centro de Córdoba | fuente Fundación Caja Madrid

patrimonio. La segunda, y esto ya no es tan razonable, es que el patrimonio de estos países está mejor gestionado, siendo el aprovechamiento cultural y turístico de sus recursos mucho mayor. $Y$ es que, como nos cuenta Xavier Greffe, la existencia de monumentos, sitios arqueológicos o paisajes, no supone ningún beneficio automático para el territorio. El público, salvo muy contadas excepciones, no demanda un bien en particular, sino el conjunto de valores y servicios que a él están asociados.

Ocurre en España que la mayor parte de los esfuerzos técnicos y económicos han estado dirigidos a la restauración en sentido estricto, y no también al conjunto de valores y servicios asociados al monumento, que carac- terizan la demanda en este sector. Se actúa mayoritariamente prestando atención sólo a la restauración, y no actuando en todas las actividades que conforman la cadena de valor del patrimonio, agregando valor al producto en cada una de ellas.

Como en la parábola de los talentos, hemos recibido cinco, pero mucho es todavía lo que nos queda por hacer para devolver diez. España, pese a su enorme riqueza patrimonial, tiene una débil imagen como destino en este mercado cada vez más importante del turismo cultural. En 2001 sólo el $10 \%$ de los extranjeros que visitaron España lo hacía por motivos culturales. En 2010 fue el 14\%. Valores muy por debajo, a pesar de su progresivo crecimiento, de los que tienen países con igual o menor riqueza patrimonial como Francia, por supuesto, pero también Reino Unido, Alemania o Austria, que superan ampliamente el $50 \%$. Desde luego esta debilidad es consecuencia de unas políticas turísticas de la Administración General del Estado centradas excesivamente en el turismo de sol y playa. Poco a poco se va corrigiendo esta política que, aunque beneficiosa en términos económicos para el conjunto de España, no lo ha sido tanto para las zonas de interior. Pero esta debilidad también es consecuencia de una política patrimonial autista.

De esta manera tenemos muchos monumentos, pero no todos son productos culturales ni son, menos aún, productos económicos. $Y$ es que sólo una parte muy pequeña del patrimonio histórico español puede considerarse como producto turístico. Córdoba, y su situación no es muy distinta a otras ciudades patrimonio mundial, tiene 97 monumentos en los planos turísticos. Sólo 12 tienen función turística principal; 7 la tienen de manera secundaria; y la gran mayoría, 78 , prácticamente no se pueden ver. ¿Qué hace falta para que un monumento sea también producto cultural y económico? Imaginemos una catedral, como hay muchas en España, y comparémosla con la catedral de Sevilla:

- La primera catedral, esta catedral imaginaria, porque no es necesario examinar a nadie, es un monumento; la catedral de Sevilla también es un monumento. 
- La primera catedral es un semiproducto cultural, cargada de tesoros y de historias, pero sin nada ni nadie que nos las cuenten (y como decía un amigo "vista una catedral , vistas todas"); la catedral de Sevilla es un producto cultural, que cuenta entre su personal laboral fijo con 60 personas entre arquitectos, arqueólogos, historiadores del arte, archiveros y bibliotecarios, albañiles, jardineros, electricistas y guías o vigilantes.

- La primera catedral no es un producto económico; la catedral de Sevilla es una empresa: genera unos seis millones de euros anuales sólo con la venta de entradas.

Se podrá objetar, con parte de razón, que no todas las ciudades son como Sevilla ni tienen una catedral así. Pero no se trata de que la demanda directa de uso y consumo de un bien concreto satisfaga los elevados costes necesarios para mantener la oferta. Eso será posible en unos casos y en otros, la mayoría, no. Se trata de tener una visión de conjunto y de que, en su conjunto, el mercado del turismo cultural sea más amplio y eficiente.

Porque en este ámbito del patrimonio hay, a grandes rasgos, dos tipos de monumentos: los monumentos que en cierto modo son como La Meca, que son los pocos que todo ciudadano tiene que ver, porque sí, una vez en la vida. Y todos los demás, en los que la demanda está en función de la calidad de la oferta, resultando por ello paradójico la poca atención que el gestor presta a la economía y al turismo. Y la oferta de turismo cultural no puede ser pasiva, limitándose, y no siempre como hemos visto, a abrir las puertas.

Veamos otro ejemplo comparando dos monumentos que ni están en Sevilla ni son como la catedral de Sevilla. El acueducto de los Milagros y el Pont du Gard:

- El acueducto de los Milagros es un monumento; El Pont du Gard también. Y en ambos parece difícil, ya que están en mitad del campo, encontrarles rentabilidad cultural y económica. ¿Qué hacemos con estos acueductos, especialmente con el del Pont du Gard, que no tiene

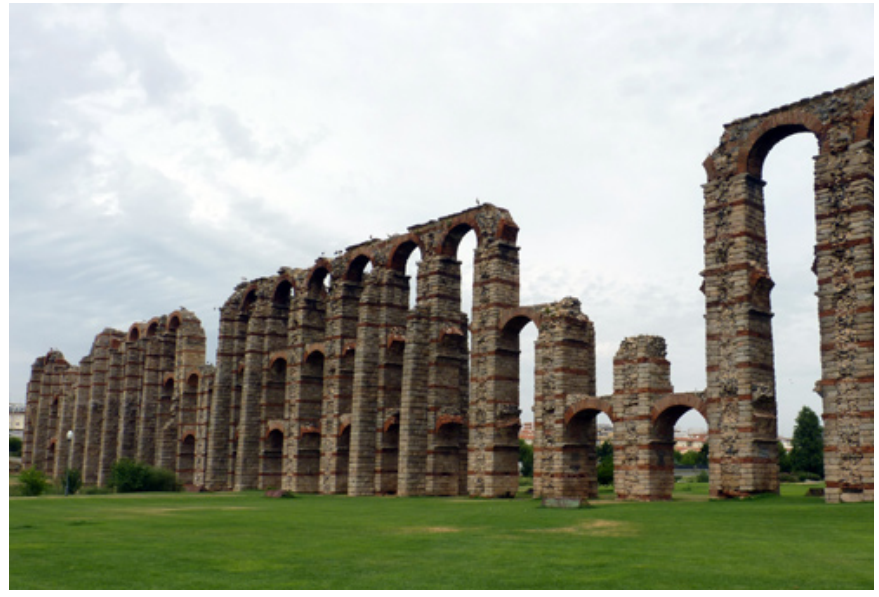

Acueducto de los Milagros, Mérida (Badajoz) | foto Rafael del Pino

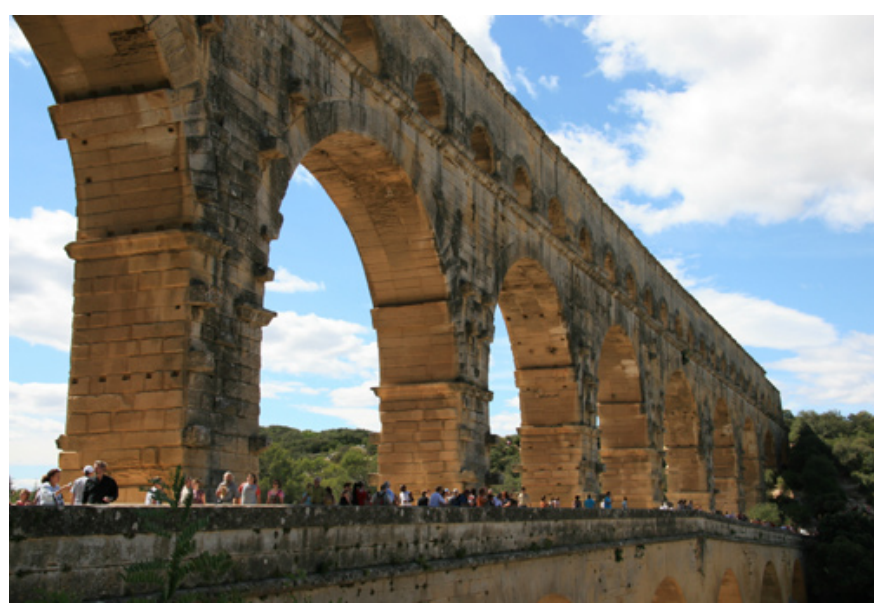

Pont du Gard, en la región francesa de Languedoc-Roussillon | foto HamburgerMichel

ninguna población cercana y está en una agreste zona?

- El acueducto de los Milagros apenas es un semiproducto cultural; el Pont du Gard es un producto cultural y paisajístico que abarca 165 hectáreas gestionadas bajo la marca Grand Site de France.

- El acueducto de los Milagros no es un producto económico; en el Pont du Gard cuesta 18 euros entrar y el sitio recibe 1.400 .000 visitantes anuales, cuyo impacto económico en una zona de la Francia rural es, como pueden suponer, enorme. 
a debate ¿el patrimonio cultural en crisis? ¿y ahora qué? | coordina Gabriel Morate Martín

O pensemos en el Duero. El Duero de los castillos, de la Reconquista, de los monasterios, de la repoblación, de las villas, del vino o de Machado, y en el Loira. El valle del Loira es el mayor monumento de Francia, con una superficie de $800 \mathrm{~km}^{2}$ e inscrito en la lista de Patrimonio Mundial; el valle del Duero es un accidente geográfico. Afortunadamente, no tenemos que ir muy lejos para demostrar que cuando la gestión del patrimonio incorpora su dimensión económica y se hace bajo planteamientos innovadores, se consigue la eficiencia cultural y social. Y ahí está el ejemplo de Atapuerca: un yacimiento irrelevante socialmente en los años 70 y 80 , convertido en un referente social, cultural, científico y turístico a finales de los 90 .

Con estos ejemplos no se quiere decir lógicamente que el modelo de gestión de todas las catedrales deba ser el de la catedral de Sevilla, ni que en el acueducto de los Milagros haya que hacer algo similar a lo hecho en el Pont du Gard. Simplemente se pretende transmitir que las respuestas que tradicionalmente existían para responder a los problemas de la conservación del patrimonio ya no nos valen. Y que el gran reto pendiente está por tanto en una gestión del patrimonio que se sirva de la economía y del turismo para el mejor cumplimiento de sus fines.

Como es sabido, el turismo, junto a sus efectos positivos, puede también poner en riesgo la conservación del patrimonio y hacer inviable la correcta transmisión de sus valores. Pero este axioma tan recurrente no debe servir para proscribir la economía y el turismo de la gestión del patrimonio, sino todo lo contrario.

Primero porque este tipo de turismo masivo se da en muy pocos sitios, pudiéndose contar en España con los dedos de la mano los monumentos, sitios o ciudades que tienen problemas de masificación.

Segundo, porque en Europa, como afortunadamente también en España, no tenemos los problemas que acarrea este tipo de turismo en sitios como Gizeh, Machu Picchu, Ankor y Teotihuacan. Porque nadie puede negar que, pese a la masificación, Venecia es una de las ciudades mejor conservadas del mundo, el Louvre uno de los mejores museos o la Alhambra uno de los mejores conjuntos monumentales.

Por ello la innovación en el ámbito del patrimonio no es una opción para ser más competitivos, sino una acuciante necesidad en una doble dirección:

- Innovación para hacer económicamente viable la conservación de tanto patrimonio, desarrollando nuevas políticas de fomento, hasta ahora centrada en la subvención a fondo perdido, que pongan el acento en la conservación preventiva, en el mantenimiento continuado y en la gestión eficiente.

- E innovación para ampliar y mejorar el comportamiento de la demanda de conocimiento y turismo cultural, a través de una oferta patrimonial planificada con visión territorial, de calidad y sometida, ojo, a una evaluación de su formulación y resultados rigurosa.

Una oferta que sea capaz, en primer lugar, de convertir nuestros monumentos en productos culturales y económicos. Agregando valor con imaginación a cada una de las actividades que conforman la gestión del patrimonio y con una política de accesibilidad y precios realista, planificada y coherente.

Una oferta, en segundo lugar, capaz también de adaptar los comportamientos de la demanda a las necesidades de preservación y transmisión de los valores culturales. De modo que ésta, la demanda, tenga tan difícil el mero consumo turístico como fácil el acceso a la cultura a través del patrimonio: derecho consagrado en nuestra Constitución cuya garantía se encomienda a los poderes públicos. 
a debate ¿el patrimonio cultural en crisis? ¿y ahora qué? | coordina Gabriel Morate Martín

\section{BIBLIOGRAFÍA}

- ALONSO HIERRO, J.; MARTín FERNÁANDEZ, J. (2000, 2004 y 2008) Conservación del patrimonio histórico desde una perspectiva económica. Madrid: Fundación Caja Madrid, 2008

- ALONSO HIERRO, J.; MARTíN FERNÁNDEZ, J. (2010) Un análisis económico de la conservación del patrimonio histórico de España. Patrimonio Cultural de España, n. 3 , 2010, pp. 31-173

- ARRIETA, URTIZBEREA, I. (ed.) (2012) Museos y turismo: expectativas y realidades. Bilbao: Universidad del País Vasco, 2012

- GILABERT GONZÁLEZ, L. M. (2012) La gestión de museos: análisis de las políticas museísticas en la península ibérica. Murcia: Universidad de Murcia, 2012

- GREFFE, X. (1990) Valeur economique du patrimoine. París: Anthropos, 1990

- HERRERO PRIETO, L. C. (2001) Economía del patrimonio histórico. ICE. Economía de la cultura [en línea], n. ${ }^{\circ} 792,2001$, pp. 151-168. <http://www.revistasice.com/CachePDF/ICE 792_151-168_A11B0C4F6C74891BDA1BF049B79D894B. pdf> [Consulta: 09/07/2013]

- MORATE MARTíN, G. (2008) La gestión del patrimonio histórico más allá de su dimensión material. Restauro: Revista internacional del patrimonio histórico, n. ${ }^{\circ}$ 1, 2008, pp. 22-25

- MORATE MARTín, G.; PRIETO, J. C. (dir.) (2010) Informe La innovación en el sector del patrimonio. Fundación COTEC

- PRATS, LI. (2012) El patrimonio en tiempos de crisis. Revista Andaluza de Antropología [en línea], n. 2, 2012, pp. 68-85. $<$ http://www.revistaandaluzadeantropologia.org/uploads/raa/ n2/lprats.pdf> [Consulta: 09/07/2013]

- PRIETO DE PEDRO, J. (2002) Cultura, economía y derecho, tres conceptos implicados. Pensar Iberoamericana [en línea], n. ${ }^{\circ}$ 1, 2002. <http://www.oei.es/pensariberoamerica/ric01a04. htm> [Consulta: 09/07/2013]

- RAUSELL, P. (2010) La privatización de bienes culturales. ¿Una alternativa? Patrimonio cultural de España, n. ${ }^{\circ} 3,2010$, pp. 109-128

- THROSBY, D. (1999) Cultural capital. Journal of cultural economics, vol. 23(1), 1999, pp. 3-12

- TROItiño, M. A. (2007) Estudio de funcionalidad del antiguo convento de Santa Clara en el contexto turístico de Córdoba. Departamento de Geografía Humana de la U. Complutense de Madrid y Fundación Caja Madrid (inédito)

- VICENTE HERNÁNDEZ, E. (2007) Economía del patrimonio cultural y políticas patrimoniales. Madrid: Instituto de Estudios Fiscales, 2007

\section{OTRAS FUENTES BIBLIOGRÁFICAS}

- Informes anuales Egatur y Familitur

- Cuenta Satélite de Turismo

- Anuarios de estadísticas culturales del Ministerio de Educación, Cultura y Deporte 